\title{
Desplazamiento cultural y procesos literarios en las letras hispanoamericanas contemporáneas: la literatura hispano- canadiense $^{1}$ \\ Literary and cultural displacement processes in contemporary SpanishAmerican letters: the Spanish-Canadian literature
}

\author{
Elena C. Palmero González
}

Recibido: 15 de Julio 2012. Aprobado: 20 de agosto de 2012

\begin{abstract}
Resumen
En este ensayo la autora presenta algunos resultados de su estudio de literaturas hispánicas producidas en ejes americanos no hispánicos, con particular interés por la literatura hispano-canadiense. Las bases teóricas que dan sustento a la propuesta historiográfica, ofrecen algunas claves generales para una caracterización del sistema hispano-canadiense, en sus coordenadas diacrónicas y en sus poéticas. Así como el análisis que visualiza la cultura en sus dinámicas de movilidad y descentramiento. Refuta los esencialismos identitarios en pro de reconsiderar, desde el nuevo ámbito de la cultura translocal y posmoderna, el enfoque de nociones que dominaron el pensamiento moderno como exilio, diáspora, migración.
\end{abstract}

Palabras clave: Literatura hispano-canadiense; Cultura translocal.

\begin{abstract}
In this paper the author presents some results of their study of Hispanic literature produced in non-Hispanic Americans axes, with particular interest in the Spanish-Canadian literature. The theoretical foundations that underpin the historiographical proposal, offer some general characterization of the keys to a Spanish-Canadian system, in its diachronic coordinates and its poetics. Analysis and displaying culture in its dynamic mobility and runout. Refutes the essentialist identity to reconsider, from the new field of translocal and postmodern culture, the focus of notions that dominated modern thought as exile, diaspora, migration.
\end{abstract}

Keywords: Spanish-Canadian literature; Translocal culture.

Interesada en estudiar textos y subsistemas literarios que por razones de diversa índole no se "localizan" en los ejes tradicionales de representación geopolítica e historiográfica, nacidos como consecuencia de las diversas formas de movilidad cultural que caracterizan

\footnotetext{
${ }^{1}$ Texto de la ponencia presentada en las X Jornadas Andinas de Literatura Latinoamericanas, Cali, 2012. Esta participación contó el con apoyo financiero de la CAPES- Coordenação de Aperfeçoamento de Pessoal de Nivel Superior, de Brasil.
} 
nuestra contemporaneidad y que ponen en crisis los tradicionales conceptos de cultura, literatura y lengua nacional - entendidas como unidades monolíticas y directamente asociadas a las nociones de Estado y territorio nacional- mi trabajo de los últimos años se ha venido centrado en el estudio de literaturas hispánicas producidas en ejes americanos no hispánicos, con particular interés por la literatura hispano-canadiense.

En esta comunicación ${ }^{2}$ presento algunos resultados de ese trabajo, fundamentalmente referidos a las bases teóricas que dan sustento a mi propuesta historiográfica, ofreciendo algunas claves generales para una caracterización del sistema hispano-canadiense, en sus coordenadas diacrónicas y en sus poéticas.

Parto, en principio, de que para iniciar cualquier estudio de producciones literarias en condiciones de desplazamiento cultural, se hace imprescindible una plataforma de análisis que visualice la cultura en sus dinámicas de movilidad y descentramiento, ajena a esencialismos indentitarios, a nacionalismos raquíticos, dispuesta a reconsiderar el enfoque de nociones que dominaron el pensamiento moderno, como exilio, diáspora, migración, procesos de filiación/afiliación, ahora recolocadas en el nuevo ámbito de una cultura translocal y posmoderna.

En la búsqueda de esa plataforma teórica, James Clifford nos ofrece una herramienta poderosa, al hacer del desplazamiento un punto de articulación de todo su pensamiento sobre la cultura. En Dilemas de la Cultura. Antropología, literatura y arte en la perspectiva posmoderna (1995) Clifford inicia una reflexión, que tendrá productiva continuidad en su obra posterior, centrada en la pregunta de cómo estudiar la cultura cuando esta se ha adaptado al movimiento. Su propuesta en este libro es la de estudiar la cultura como "una forma perpetuamente desplazada [....], una forma de residir y viajar al mismo tiempo" (1995, p.16). Si tradicionalmente se concibe la residencia como la base de la vida colectiva y el viaje como su suplemento, Clifford subvierte ese razonar y se pregunta si las prácticas de desplazamiento no podrían aparecer como constitutivas de significados culturales, en lugar de ser su simple extensión o transferencia.

De la misma manera, el desplazamiento articula una noción de identidad en la propuesta del antropólogo norteamericano. Su idea de identidad no se refiere a un local, sino que está

\footnotetext{
${ }^{2}$ Desarrollo en estos momentos un proyecto beneficiado con beca de investigación del CNPQ de Brasil, cuyo objetivo es establecer bases teórico-metodológicas para una sistematización historiográfica del corpus hispano-canadiense en el proceso de las literaturas hispo-americanas contemporáneas.
} 
relacionada con la deslocalización y relocalización. En su perspectiva, estudiar hoy identidades significa considerar que ellas no presuponen culturas o tradiciones continuas, pues por todas partes los individuos improvisan realizaciones locales a partir de pasados recoleccionados, recurriendo a medios, símbolos y lenguajes extranjeros, de manera que vivimos una existencia entre fragmentos móviles.

Esa perspectiva no esencial de la cultura y de la identidad estará también presente en su libro Itinerarios Transculturales (1999), en el que vuelve a la idea de que vivimos "una residencia en viaje" (p.12). En esta obra traza una imagen de la ubicación humana, constituida en la doble articulación del desplazamiento y la fijación, sometiendo a juicio el supuesto de que preexista una esfera local anterior al desplazamiento, pues para él "los centros culturales, las regiones y territorios delimitados, no son anteriores a los contactos, sino que se afianzan por su intermedio" (p.14). Desde esa posición descentradora, Clifford alimenta la idea de una cultura "translocal"- ya no global ni universal- para dar cuenta de las múltiples intersecciones que se producen entre procesos locales, regionales y globales en condiciones de amplia comunicación masiva y movimiento humano, situando así la cultura en una vasta red de relaciones transversales, complejas, móviles y multidireccionales.

Su estudio de identidades y formaciones comunitarias en desplazamiento, entendidas como comunidades translocales abre también una sostenida crítica a las teleologías del regreso, de tanto peso en las interpretaciones más tradicionales de la diáspora. Lejos de cualquier absolutismo nacionalista o binarismo excluyente, su discurso del desplazamiento atiende a lo proliferativo y fecundante de todo contacto cultural, para afirmar que las identidades diaspóricas, fronterizas e híbridas tienden a unir idiomas, tradiciones, imaginarios, siempre de manera creativa, "articulando patrias en combate, fuerzas de la memoria, estilos de trasgresión, en ambigua relación con las estructuras nacionales y transnacionales" (p.21). En la misma dirección de pensamiento, la perspectiva cultural de Stuart Hall (2003) pone en crisis una concepción de diáspora afincada en las teleologías del origen y en una concepción binaria y esencialista de la diferencia. Hall coloca bajo sospecha la idea de que sea posible localizar un origen "homogéneo" y "auténtico", sobre todo para el mundo americano, constituido de rutas impuras y camadas de diásporas, al tiempo que propone la diférrance como alternativa para pensar la diferencia cultural, entendida derrideanamente, 
como un juego de significados siempre postergados, relacionales e intercambiables. Su idea de cultura como producción, no como arqueología; como algo que permanentemente estamos construyendo, apunta para el lado móvil y creativo del concepto, ciertamente el que más me interesaría destacar para acometer mi trabajo. Para Hall, las estéticas diaspóricas son naturalmente impuras, reutilizan materias primas, recodifican lenguajes, interactuando con las culturas de adopción, de las que se alimentan y a las que alimentan, por eso son estéticas de la fertilización.

Completando esta visión, rescato un ángulo del pensamiento de Silviano Santiago (2000) cuando lee la cultura latinoamericana y el lugar cultural del intelectual latinoamericano desde lo entre-lugar. Al privilegiar las múltiples exclusiones, el "entre-lugar" de Santiago desterritorializa lo nacional, entendida la nación como sistema orgánico y total dentro de una historia lineal. Su articulación de lo local, lo nacional y lo global ajena a esencialismos eurocéntricos, su ruptura con la primacía del concepto de origen, su crítica a los conceptos de unidad y pureza en la cultura, su visión proliferativa y fecundante de nuestro continente, un continente que el crítico brasilero ve en un permanente "desvío de la norma", me parecen conceptualizaciones imprescindibles en este momento en que sistematizo algunas ideas en torno a la propia noción de cultura como antesala para un estudio de las literaturas de las diásporas hispanoamericanas.

Y saliendo del ámbito americano, pero en una misma comunidad de pensamiento, rescato de Edward Said (1983) aquella idea de cultura como posesión en contraposición a la noción cartesiana de pertenencia. Para Said la cultura es algo que se tiene, no a lo que pasivamente se pertenece, distinguiendo así la "filiación" de la "afiliación", la primera, como pertenencia invariable, la segunda como un concepto de opción, no biológico o esencialista, relativo a las culturas en dispersión, siempre proliferantes, prospectivas, creativas y fecundantes.

Situadas estas rápidas coordenadas en torno a una idea de la cultura en condiciones de amplia movilidad, se hacen necesarias algunas precisiones relativas al propio concepto de desplazamiento que reiteradamente he venido usando y que se anuncia como punto focal de reflexión en el título de este ensayo. En el verbete que preparé para el Diccionário das movilidades culturais: percursos americanos, organizado por Zilá Bernd (2010) traté con rigor teórico el tema. Retomo de ese trabajo las primeras líneas, cuando afirmo: "Pensar la 
noción de desplazamiento en el ámbito de las ciencias sociales, y específicamente en la órbita de los estudios de la cultura, significa remitirnos a diferentes formas de movilidad, física, espiritual, lingüística; a diversas prácticas de emigración, exilio, diáspora, éxodos, nomadismos, circulaciones humanas; es pensar en traslado y en tránsitos de todo tipo, en políticas del movimiento y en economías del viaje. Entendido como vivencia y práctica de los sujetos, el desplazamiento es un concepto fundamental en los estudios sobre imaginario y memoria cultural. Entendido como metodología de trabajo, deviene un paradigma fundamental para pensar procesos culturales" (2010, p.109). O sea, uso el concepto en su sentido más amplio y abarcador, articulando con él las variadas formas de la movilidad, como las diásporas, los exilios, las migraciones, los intercambios de signos, símbolos y valores que fluyen en las redes sociales, en las comunidades virtuales, pero también, y acaso sea lo más importante, entendido como locus de enunciación, como poética de la escritura y como paradigma crítico e historiográfico para estudiar las literaturas producidas en condiciones de movilidad cultural.

De igual manera, me permito un rápido comentario en torno al segundo foco apuntado en el título de este trabajo, el referido a la idea de proceso literario y al entendimiento de los procesos literarios en Hispanoamérica. Recupero, en principio, la vieja preocupación de Tynianov por la procesualidad, la variabilidad y las nociones de cambio y conflicto dentro del marco literario; atiendo su crítica a un concepto de evolución literaria como proceso lineal, progresivo y sin contingencias; y explicito mi filiación al pensamiento de Antônio Cândido (1997) y de Cornejo Polar (1997) cuando asumen la visión de proceso como única perspectiva para rescatar un trabajo crítico e historiográfico focalizado en la movilidad, la heterogeneidad de los repertorios, la conflictividad y en la interacción cultural. Es la perspectiva de Ana Pizarro en La literatura como proceso (1985), un libro que rescata de manera particular este tema del movimiento de la cultura latinoamericana como proceso de perfiles irregulares, de tiempos y espesores heterogéneos, visualizando nuestra literatura como un gran campo discursivo, en el que se cruzan obras, productores literarios, receptores y la propia lengua en una amplia red de temporalidades. Como afirma la historiadora de la literatura chilena, una visión de proceso implicaría estudiar "la diversidad de culturas y de ritmos temporales, los sistemas de coincidencias e interrelaciones, el 
dinamismo entre las continuidades y las rupturas, en suma [hacer] una historia de nuestra literatura consciente de la heterogeneidad esencial que sustenta su discurso" $(1985$, p.9).

Inmersa en esa manera de entender la cultura, los procesos literarios, y especialmente afín a esa manera de entender los desplazamientos contemporáneos, me pregunto:

- ¿Qué ocurre cuando la variable nacional, de larga tradición crítica en nuestros estudios literarios latinoamericanos se presenta como una variable en crisis, actualmente afectada por los movimientos migratorios, la comunicación virtual, el permanente tránsito de imágenes y por la propia crisis de las nociones de nación, estado o territorio nacional?

- ¿Cómo estamos enfrentando el estudio de las literaturas hispanoamericanas que se producen hoy en condiciones de amplia movilidad cultural?

- ¿Cómo las experiencias diaspóricas y en general las prácticas de desplazamiento pueden transformar nuestras propuestas de una historia de la literatura?

Sin ánimo de respuestas definitivas, articulo algunas reflexiones, o más bien diría que intento acomodar la mirada para entender un complejo sistema literario como el hispanoamericano, entenderlo en sus diálogos, en sus discontinuidades, en sus relaciones intersistémicas y especialmente, entenderlo en sus dinámicas contemporáneas del movimiento y el intercambio simbólico. Desde esa perspectiva mayor, focalizo un corpus literario concreto, a partir del cual poder ajustar las lentes: el sistema hispano-canadiense. Si coloco la mirada en la singularidad, es porque en el fondo late la intensión de entender un proceso literario mayor.

La literatura hispano-canadiense se articula con cierta nitidez en los últimos sesenta años. Producida por una comunidad emigrada de origen hispánico en el ámbito geográfico de Canadá, ella ha venido alcanzando gradual visibilidad y legitimación institucional en las últimas décadas, sobre todo a partir de la atención que la crítica comienza a darle en el propio ambiente hispano-canadiense y de su presencia en los medios académicos canadienses y norteamericanos.

Lamentablemente la crítica producida en ambientes hispánicos de América Latina, no ha atendido con el mismo interés este corpus, ni siquiera aquella más próxima de la crítica cultural y los estudios subalternos, preferencialmente interesada por las literaturas de lengua española producidas en Estados Unidos. 
También la sistematización de este corpus en los proyectos historiográficos hispanoamericanos se presenta hasta hoy como un vacío. Son sus "parientes cercanas", las literaturas hispanas dentro del territorio estadounidense, las que gozan de una mayor atención, particularmente la literatura chicana, la neuyorican y las llamadas "literaturas del exilio" o "literaturas de la diáspora hispánica".Solo como ilustración, pensemos en los proyectos historiográficos más serios de los últimos años, la historia de la literatura latinoamericana de Roberto González Echevarría y Enrique Pupo-Walker, The Cambridge History of Latin American Literature, de 1996, corregida y ampliada para Gredos en 2006, y la coordinada por Mario Valdés y Djelal Kadir con participación de un nutrido grupo de investigadores de América Latina, me refiero a los tres volúmenes de la Literary Cultures of LatinAmerica. A Comparative History (2004). La primera dedica dos excelentes capítulos de su segundo volumen a la literatura hispano-caribeña escrita en los EU y a la literatura chicana. La segunda articula en sus tres volúmenes una historia de la heterogeneidad cultural en América Latina, jerarquizando lo transnacional en su concepción, si bien los ensayos reunidos circulan siempre por los ejes hispánicos de Europa y Estados Unidos. Sorprendentemente, no encontraremos mención en estos proyectos a la diáspora hispánica en Canadá y su producción literaria.

Anótese también que Ana Pizarro (2004), en su propuesta de áreas culturales para el estudio de las producciones culturales en América Latina, se refiere a una zona cultural transnacional y multilingüe que se configura con la emigración de escritores hispanoamericanos para EU en el siglo XX, sin otras alusiones al eje hispano-canadiense.

Advierto que esta observación, lejos de constituirse en una crítica a estos proyectos, que considero extraordinariamente valiosos en el campo de la historiografía literaria hispanoamericana contemporánea, la sitúo como un punto de partida que me permita articular mi trabajo a las dinámicas metodológicas que precisamente estas historias literarias proponen. Concebidas a partir de un criterio historiográfico ajeno a las totalizaciones, en diálogo abierto con lo hipertextual y privilegiando lo translocal, ellas me ofrecen un valioso horizonte para poder pensar una realidad cultural y una producción literaria como la hispano-canadiense.

Las primeras muestras de lo que hoy llamamos literatura hispano-canadiense, según nos informa Hugh Hazelton en su libro Latinocanadá (2007), hay que localizarlas en la 
comunidad de escritores españoles que llegaron a Canadá tras la Guerra Civil. Los iniciales esfuerzos de estos primeros emigrados por crear un ambiente literario de expresión hispánica están en la revista trilingüe Boreal. Editada en Montreal, la revista publicó entre 1965 y 1970 poetas españoles emigrados, pero a partir de 1970 comenzó a publicar la obra de escritores latinoamericanos que llegaban a Canadá como exiliados políticos de los regímenes dictatoriales y represivos del sur de América.

Hazelton señala que es esta segunda oleada de escritores hispanohablantes, la que llega en torno de los años setenta, la que comienza a darle cuerpo y consistencia a la literatura hispano-canadiense. Estos emigrados, a diferencia de los primeros, pasan a radicarse permanentemente en el país, hacen vida de comunidad y publican de manera estable en territorio canadiense. Con ellos, una actividad editorial coherente comienza a abrirse paso a fines del setenta e inicios de los años ochenta, siendo las ciudades de Montreal y Ottawa los dos ejes que protagonizan este movimiento. Por solo citar algunos ejemplos, es el momento en que empiezan a dar a conocer sus textos escritores que hoy gozan de una sólida y reconocida obra como Pablo Urbanyi, Leandro Urbina o Nela Rio.

Los conflictos políticos y económicos en las décadas siguientes en América Latina traerían nuevos emigrantes del resto del continente americano. Este nuevo grupo no solo se localizó en los tradicionales centros urbanos-universitarios como Ottawa, Toronto, Montreal o Vancouver, sino que significativamente comenzó a ubicarse en pequeñas comunidades universitarias como las de Calgary, Edmonton o Winnipeg. Es el momento en que proliferan las pequeñas editoriales hispánicas y cuando se generaliza la publicación de autores hispanohablantes en Canadá. También es la época en que las letras hispanocanadienses comienzan a despertar el interés editorial del ámbito anglófono y francófono. Este interés editorial estará relacionado con un sistemático trabajo de traducción, línea que no puede perderse de vista a la hora de un balance institucional de la literatura hispanocanadiense.

En los últimos quince años, entrando en el nuevo siglo, la emigración de escritores hacia Canadá se produce bajo otras condiciones culturales e históricas. Ya no es mayoritaria la experiencia de los exilios forzados, ni de los retornos imposibles a la tierra natal. Predomina ahora un tipo de emigración electiva (razones de trabajo o de estudio, por ejemplo), que crea comunidades afectivas de otra naturaleza, no exactamente asociadas al 
trauma y la violencia política que fueran dominantes en décadas anteriores. El acelerado desarrollo de internet y de otros medios de comunicación, con sus nuevas subjetividades, nuevas experiencias comunitarias y nuevas formas de imaginación van transformando la vivencia diaspórica, y todo eso resulta en un escritor cosmopolita, de escritura bilingüe y a veces trilingüe; un intelectual puente, permeable y de fronteras difusas; que se declara ciudadano del mundo, con fuertes conexiones con su tierra de origen, al tiempo que también con Canadá o con los grandes ejes editoriales del mundo.

Súmese a esto el hecho de que ya comienza a aparecer una nueva generación de escritores de origen hispanoamericano nacidos en Canadá, o que emigraron niños, como es el caso del novelista quebequense Mauricio Seguro o del dramaturgo de Vancouver Guillermo Verdecchia. Para estos escritores, la cohabitación de culturas no es conflictiva, se regodean en su condición anfibia y ni siquiera se plantean las preguntas identitarias de sus antecesores. La lengua literaria que eligen es el inglés o el francés, si bien son sujetos bilingües y biculturales pues nacieron en hogares hispánicos y tuvieron su educación en instituciones canadienses.

Gustavo Pérez Firmat (2000), pensando en la literatura cubano-americana, llama a este tipo de producción literaria de "literatura étnica", para distinguirla de la literatura inmigrante y de la exiliada. En su clasificación, no exenta de polémica, Firmat define el escritor étnico como un sujeto que cultiva la diferencia y la marginalidad, sin crisis, disfrutando su dualidad. Pienso que al margen de cualquier observación, puede ser funcional su percepción de como el enraizamiento, consustancial a la migración, produce un nuevo sujeto y consecuentemente un nuevo tipo de escritura, inmersa en el bilingüismo, con otras coordenadas estéticas y en otras tensiones ideológicas.

Esa superposición temporal de camadas generacionales, provenientes de regiones tan diversas como Centroamérica, América del Sur o el Caribe, con vivencias culturales específicas, formaciones estéticas particulares, con sus propios códigos, sus repertorios literarios, dan al sistema un perfil definitivamente heterogéneo. No obstante, esa diversidad no afecta su sentido de unidad. A diferencia de las literaturas de lengua española producidas en Estados Unidos, que se presentan como unidades con cierta autonomía institucional, reproductoras de una identidad nacional en dislocación (la literatura cubana, chicana, portorriqueña, por ejemplo), los escritores hispano-canadienses se reconocen como 
comunidad y la institucionalización literaria de esa producción se da de una manera mucho más armónica. Digamos que la heterogeneidad es asumida como rasgo identitario.

Un elemento que debe dejarse apuntando a propósito de la constitución heterogénea del sistema hispano-canadiense es que este se produce en contacto con otras comunidades emigradas, con las que permanentemente dialoga y se retroalimenta estéticamente. De hecho, esta literatura es parte de un gran sistema latino-canadiense, o sea que tiene relaciones naturales con otras literaturas no hispánicas latinoamericanas (caribeños francófonos e anglófonos, por ejemplo) e incluso con grupos que ni siquiera tienen un tronco latino pero que comparten igualmente las estéticas del desplazamiento. Y considerar también que el asentamiento de estos escritores se produce en una tierra con dos ejes culturales hegemónicos, el anglófono y el francófono, con los que permanentemente han tenido que negociar.

En la misma dirección, el idioma, tradicionalmente asociado al concepto de unidad de una literatura, ha ido entrando también en un rico proceso de negociación. La escritura en dos lenguas comienza a ser una realidad para los escritores hispano-canadienses, como lo expresa Martha Bátiz cuando afirma: “disfruto escribir en inglés y estoy convencida de continuar combinando la escritura en ambos idiomas" (Molina/ Torres Recinos, 2008, p.25). En algunos casos ese proceso asimilativo se ha convertido en una estética, con la asunción del spanglish como praxis creadora. También aparece hoy una escritura en inglés o francés culturalmente inmersa en el universo hispanoamericano, con la que la historiografía literaria tendrá que lidiar de manera más diáfana.

Este espectro presentado aquí de manera sucinta, dará la medida de la configuración de ese sistema literario. Si por un lado, razones de lengua, de origen, de experiencias próximas de emigración y diáspora, así como afinidades estéticas ostensibles entre los escritores que participan de esa praxis, dan perfil al conjunto; por otro, no podemos soslayar el hecho de que trabajamos con un objeto de naturaleza plural, inestable e irreducible a arquetipos tradicionales de identificación.

Presentadas estas coordenadas diacrónicas, propongo una mayor atención a las poéticas y prácticas de escritura que suelen tener más sistematicidad en la literatura hispanocanadiense contemporánea. Si en esta parte tiendo a las generalizaciones, advierto que la diversidad irreductible de ese corpus y los límites de este trabajo no me permiten mucho 
más que situar algunos nodos que me parecen centrales para cualquier intento caracterizador de la actual literatura hispano-canadiense.

Procurando uno de esos nodos, vuelvo al tema del desplazamiento como poética de la escritura, un tema que he venido desarrollando en algunos ensayos y que aun es un trabajo en proceso, no solo mío, también de otros investigadores como Hugh Hazelton (2007) o Norman Cheadle (2007). No obstante arriesgo algunos comentarios.

En un intento de sistematizar una posible poética del desplazamiento, distinguiría en particular, un rasgo que tiene una decisiva presencia en el corpus contemporáneo de la literatura hispano-canadiense: la articulación de una cronotopía imaginaria, en la que parecen cruzarse tiempos y espacios profundamente ambiguos, sin límites precisos, ni referencias inmediatas en la realidad sensible; donde se interceptan de manera altamente imaginativa la tierra matricial y la de acogida; el pasado y el presente; el recuerdo y el olvido; una cronotopía expresiva de la productiva asimilación de lo móvil y lo arraigado que hay en toda experiencia migrante, y expresiva de lo inventivo de la memoria, si con Bachelard entendemos la memoria como imagen en movimiento.

Encontraremos así, textos que circulan por los arquetípicos tópicos del viaje, el regreso, los sueños, a través de imágenes que restauran un paraíso perdido, en referencia tal vez más inmediata a un origen; textos que legitiman tiempos y espacios contemporáneos de tránsito, como aeropuertos, llamadas telefónicas, salas online de redes sociales; y textos en los que toda referencia a un origen es totalmente elidida. En estos últimos cobran singular protagonismo los cronotopos del cuerpo y de la propia escritura.

En la órbita de una literatura centrada en los motivos del viaje utópico a la tierra natal, encontraremos con bastante recurrencia las heterotopias de ciudades imaginarias, las reescrituras míticas de la tierra de origen ola tematización del propio viaje como cronotopia imaginaria, así es posible leer un Cuzco legendario en los poemas de Lady Rojas, una Plata mítica en los textos de Nela Rio o una jungla absolutamente ilusoria en la original novela Silver (1993), de Pablo Urbanyi.

La reinvención del viaje, como espacio habitable, aparecerá en la experiencia poética de Yvonne Truque, en su poemario Recorriendo la distancia (2007), un libro donde el sugerente motivo de habitar la distancia nos conecta con un sujeto asumidamente híbrido, protagónico de un viaje transcultural, sin principio ni fin, viaje en sí mismo. 
El tema del regreso y sus consabidas paradojas existenciales, alcanza vuelo poético en $E l$ exilio y las ruinas (2000) de Luis Torres. Congratulado con una mención especial en el concurso Casa de Las Américas (Cuba) en 2000, el libro fabula un viaje de vuelta al país natal y las contradictorias maneras de ser extranjero en la propia tierra, actualizando aquella pregunta cara a todo exiliado: ¿a qué hogar realmente se regresa? Elocuente es el poema "Las preguntas”: ¿Encontrará su forma el cuerpo?/ ¿Será otra vez lo que ya fuera?/Exiliado de sí mismo, cuerpo en ruinas, / ¿entrará su cuerpo en otro cuerpo al volver? (P.61) Ya por otros caminos de exploración de esa cronotopia imaginaria, toma consistencia poética el tópico autorreflexivo del cuerpo, un cuerpo asumido como lugar de reconciliación y reconocimiento identitario; no como expulsión y exilio, en el sentido que la tradición occidental le confirió. Una referencia significativa en este sentido está en el universo poético de una escritora como Nela Rio. Los tópicos del cuerpo erótico, torturado o mutilado dan fundamento a un particular sistema metapoético y autoreflexivo en libros como Túnel de proa verde/Tunnel of the Green prow (1998) y Cuerpo amado/Beloved Body (2002). El primero hace de la tortura y el silencio un manantial de creación poética, camino por el cual es posible la liberación; el segundo tematiza el camino de reconocerse y aprenderse a amar en un cuerpo nuevo, un cuerpo asimétrico y devastado por el cáncer, que se erige como trofeo victorioso y desde el cual es posible decir: "Miro mi cuerpo y admiro su valor/ me habito con orgullo" (p.102).

En la misma dirección, la propia escritura como tema y materia poética ocupa un lugar dominante en esa praxis literaria. Inmersas en un tipo de literatura en la que el sujeto textual y el sujeto que escribe se miran especularmente, las escrituras de sí serán frecuentes. El escritor se inventa a sí mismo, al tiempo que habita otras identidades literarias, a través de travestimos, palimpsestos, reescrituras. Los espejos hacen preguntas/TheMirrors Ask Questions (1999) de Nela Rio se presenta, en este contexto, como un excelente ejercicio de palimpsesto y travestismo literario. Desplegando sus mapas heterotópicos sobre la propia serie literaria y la propia tradición poética, la escritora toma de manera explícita el lugar, las vestes y el discurso de Sor Leonor de Ovando, nuestra primera poeta de las letras coloniales en Hispanoamérica, desarrollando un libro especular, donde también asomarán ecos de Santa Teresa de Jesús o de San Juan de la Cruz, como si el juego de reescritura 
revelara la naturaleza palimpsestuosa de todo acto escritural. En esas transmigraciones literarias, el escritor crea un lugar habitable en su propia genealogía poética.

Las narrativas autobiográficas y las autoficciones, la metalepsis de autor, los textos autoreflexivos toman espacio en esa praxis, haciendo visible un sujeto de múltiples centros que transita libremente entre el mundo de la vida y el mundo de la ficción. En esa órbita es posible leer al protagonista innominado de la novela Cobro revertido (1992), de José Leandro Urbina, que deja pistas reconocibles en la propia biografía del escritor. Algunos críticos han hecho un cotejo de esos datos para una lectura autoficcional de la novela. Pienso que al margen de la comprobación del dato, lo más atractivo de la obra es como ella traza sus estrategias pragmáticas para ser leída en clave autoficcional.

Si en esa novela Urbina escenifica un juego autofictivo solapado, en Las memorias de Baruni (2009), su última novela, opta por el discurso memorial declarado, autorepresentándose abiertamente en el rol de escritor/editor de unas supuestas memorias que el Gordo Baruni le ha dejado como legado. Ahora solo se esconde en el anagrama de Baruni/Urbina para hacernos partícipes de unas falsas memorias. Borgianamente, el libro explicita un documento que sabemos falso, anunciando una saga de siete volúmenes, digamos que una versión seriada del "reality show" de Baruni, que sabemos Urbina.

Inmersa en la práctica de la autoreflexividad, la propia lengua se convierte para algunos escritores en lugar, un lugar inestable y fluido, donde la negociación cultural hace sus más evidentes efectos. Hace varias décadas, George Steiner, en su célebre libro Extraterritorial (2002), acuñó el término “extraterritorialidad” para referirse al paradigma estético que se crea en condiciones de desplazamiento lingüístico. Steiner se refería a escritores plurilingües que al transitar por varios idiomas, o al abandonar el materno para escribir en otro, van instaurando una nueva poética escritural. En ese sentido lo extraterritorial puede ser leído no solamente como realidad cultural y lingüística, sino también como una poética de la creación. Contemporáneamente, Steven Kellman (2010) estudia la imaginación translingüística en escritores que se mueven por varios universos lingüísticos y considera que esa posición entre lenguas les permite desafiar los propios límites de la literatura, de manera que crean una literatura signada por la movilidad.

Asumida la extraterritorialidad y el translingüismo como poéticas, será frecuente la legitimación estética del spanglish o el tránsito entre lenguas en escritores hispano- 
canadienses que, ponderando la poeticidad del lenguaje, no hacen más que expresar el desplazamiento como realidad vivida que precisa ser discursivizada.

El tránsito entre lenguas aparece en la singular escritura de Alejandro Saravia, escritor de origen boliviano para quien el inglés y el francés han entrado en convivencia armónica y natural con el español. Acaso su escritura sea el ejemplo más elocuente de translingüismo literario en condiciones de cultura translocal, de la misma manera que su figura intelectual sea una expresión elocuente del sujeto permeable y en tránsito que el campo intelectual hispano-canadiense comienza hoy a colocar en escena. Con razón Norman Cheadle (2011) lo estudia como el caso más original de una auténtica escritura interamericana.

Cabe hacer referencia también al camino inverso que despliega el escritor quebequense de origen chileno Mauricio Seguro. Su exitosa novela Cotê- des- nègres (1998), una especie de leyenda urbana sobre las ganguees de Montreal, hace del español y del creole dos universos lingüísticos deslizantes encima del francés quebequense, lengua del escritor, que convive con la coordenadas hispánicas de su formación en un hogar de padres chilenos.

En todos esos cronotopos fictivos, profundamente marcados por las dinámicas de la movilidad y la fijación, el apagamiento y la memoria, la presencia y la ausencia, es posible leer una nueva imaginación, una imaginación en movimiento, elocuentemente expresiva de las identidades transculturales de nuestro tiempo.

Partiendo de esa realidad cultural y su praxis creadora, me pregunto entonces: cómo acometer un proyecto de historiografía literaria que sistematice ese corpus, con sus estrategias de desplazamiento, en el proceso de la literatura hispanoamericana contemporánea. Esta es sin dudas una tarea de gran aliento, difícil de responder en los límites de este texto, solamente me arriesgo a dejar apuntados tres ejes que me parecen insoslayables para acometer un proyecto historiográfico de esa naturaleza:

- La conveniencia de una historia literaria comparada que privilegie lo translocal, como plataforma para acometer de manera productiva y crítica el estudio de las relaciones transversales entre lo local, lo regional, lo nacional y lo mundial a la hora de enfocar procesos literarios, partiendo, sobre todo, de la asunción del carácter conflictivo y no lineal de estas nociones.

- La necesidad de pensar los procesos literarios a partir de una concepción sistémica de la literatura, pensándolos como sistemas dinámicos, en el sentido que lo propone Itamar Even- 
Zohar (1999) con su teoría de los polisistemas literarios. Por ese camino volvemos a aquella certeza de Cornejo Polar de que no tenemos una literatura, sino verdaderos sistemas literarios, con sujetos, espacios y tiempos distintos que se infiltran en diversas instancias de nuestros procesos socioculturales.

- La necesidad de privilegiar la interliterariedad, considerando que la propuesta de proceso interliterario se basa en el reconocimiento de la imposibilidad de pensar las literaturas como territorios monológicos, sino como entidades en constante fluidez y comunicación. La realidad histórica, cultural, geográfica, social y literaria de las Américas reclama de esa mirada interliteraria e interamericana.

Y en este punto de cierre, vuelvo a Ana Pizarro cuando reflexiona:

"Estamos viviendo en las últimas décadas de este siglo nuevos procesos migratorios [...] Esta nueva situación social diseña también nuevos problemas al historiador de la cultura y la literatura. Se trata de un fenómeno que ya está teniendo sus expresiones estéticas, está deviniendo en formas y estructuras de la creación. De ese imaginario social aparecen las primeras textualizaciones, las primeras sintaxis en imágenes fílmicas. Se abre con ellos un nuevo centro de gravitación de energías culturales en el que habrá nuevos cruces, otras formas de solapamiento, tensiones que apelarán a la memoria de la migración que ha hecho de nuestra cultura lo que es, y que abrirá a nuevas problematizaciones” (2004, p.79).

Urge volver la mirada para esas realidades, ellas están ahí, reconfigurando nuestras propuestas historiográficas, nuestras cartografías literarias, nuestra propia idea de América.

\section{Bibliografia}

BERND. Zilá (org). Dicionário das mobilidades culturais: percursos americanos. Porto Alegre: Literalis, 2010.

CÂNDIDO, Antônio. Formação da literatura brasileira. Belo Horizonte: Editora Itatiaia, 1997.

CHEADLE Norman/Lucien Pelletier. Canadian cultural exchange: translation and transculturation/Échanges culturels ou Canada: traduction et transculturation

Waterloo: Laurier University Press, 2007.

CLIFFORD, James. Dilemas de la Cultura. Antropología, literatura y arte en la perspectiva posmoderna. Barcelona: Gedisa, 1995.

Itinerarios transculturales, Barcelona: Gedisa, 1999. 
CORNEJO POLAR, Antonio. Escribir en el aire. Ensayo sobre la heterogeneidad cultural en las literaturas andinas. Lima: Editorial Horizonte, 1997.

"Sistemas y sujetos en la historia literaria latinoamericana", Casa de las Américas. La Habana: Casa de las Américas. Año XXIX, No. 17, 1988, pp. 67-71.

EVEN-ZOHAR, Itamar. "Factores y dependencias en la cultura. Una revisión de la teoría de los polisistemas”. In: Iglesias Santos, M. (org), Teoría de los polisistemas. Madrid: Arco, 1999.

GONZALEZ ECHEVARRÍA, Roberto. Historia de la literatura Hispanoamericana, Gredos, 2006.

HALL, Stuart. Da Diáspora: Identidades e Mediações Culturais. Org. LivSovik; Trad.Adelaine La Guardia Resende. Belo Horizonte: Editora UFMG, 2003.

HAZELTON, Hugh. Latinocanadá.A Critical Study of Ten Latin American Writers of Canada.Montreal \& Kinston, McGuill-Queen's, 2007.

KELLMAN, Steven. The translingual imagination. Lincoln: University of Nebraska Press, 2000.

PALMERO, Elena. Deslocamento. In: Zilá Bernd (org). Dicionário das mobilidades culturais: percursos americanos. Porto Alegre: Literalis, 2010.

Palimpsesto y travestismo literario en los diálogos poéticos de Nela Rio. In: Eduardo Ramos Izquierdo/ Milagros Ezquerro. (Org.). Reescrituras y transgenericidades. Paris: Rilma2 et Adehl, 2010.

. Espaços da imaginação migrante na literatura hispano-canadense: uma topología imaginada no universo criativo de Nela Rio. In: Carrizo, Silvina; Noronha Jovita. (Org.). Relações Literárias Interamericanas: Territorio\& Cultura. Juiz de Fora: Editora UFJF, 2010.

A literatura hispano-canadense: novas geografias culturais, novas histórias da literatura na América Latina. Anais do III Colóquio Sul de Literatura Comparada, Porto Alegre, Ed. da UFRGS, 2010.

PEREZ FIRMAT, Gustavo. Trascender el exilio. Memorias recobradas. Santa Clara: Capiro, 2000

PIZARRO, Ana. La literatura latinoamericana como proceso. Buenos Aires: Centro Editor de América Latina, 1985.

El sur y los trópicos (ensayos de cultura latinoamericana). Pról. de José Carlos Rovira. Cuadernos de América Sin Nombre, Alicante, 2004. 
SAID, Edward.The World, the Text and the Critics.Cambridge: Harvard University Press, 1983.

SANTIAGO, S. "O entre-lugar do discurso latino-americano". In: Uma literatura nos trópicos. Rio de Janeiro: Rocco, 2000.

STEINER, George. Extraterritorial: a literatura e a revolução da linguagem. São Paulo: Companhia das Letras, 1990.

TORRES, Luis. "WritingsoftheLatin-Canadian Exile". Revista Canadiense de EstudiosHispánicos 26.1-2, otoño 2001-invierno 2002.

.El exilio y las ruinas. Santiago: RIL Editores, 2002.

VALDÉS, Mario/ DjelalKadir (eds.): Literary Cultures of Latin America. A Comparative History.3 Vols. New York/Oxford: Oxford University Press, 2004. 